Original Article

\title{
PRESCRIPTION PATTERN OF CARDIOVASCULAR AND/OR ANTIDIABETIC DRUGS IN ABUJA DISTRICT HOSPITALS
}

\section{NKEIRUKA GRACE OSUAFOR*, CHINWE VICTORIA UKWE, MATTEW JEGBEFUME OKONTA}

Department of Clinical Pharmacy and Pharmacy Management, Faculty of Pharmaceutical Sciences, University of Nigeria, Nsukka, PMB 410001 Enugu State, Nigeria

Email: nkeiruka.osuafor.pg76799@unn.edu.ng

Received: 10 Jun 2019 Revised and Accepted: 25 Jul 2019

\section{ABSTRACT}

Objective: The study aimed to describe the prescription pattern of cardiovascular and/or anti-diabetic drugs and adherence to the World Health Organization (WHO) prescribing indicators in Abuja District Hospitals.

Methods: This descriptive retrospective study was carried out in Asokoro and Maitama District Hospitals Abuja. One thousand and nine prescriptions that contained a cardiovascular drug (CVD) and/or anti-diabetic drug issued between June 2017 and May 2018 from the Medical Outpatient Department were analyzed. Data were collected from the pharmacy electronic database, prescription pattern and adherence to WHO prescribing indicators were assessed. The analysis was done using descriptive statistics. Results were presented as percentages, means, and standard deviations.

Results: The frequency of treatment was higher among women (58.8\%) and the age group of 41-60 (54.8\%). The average number of drugs prescribed was 3.3 \pm 1.6 : the percentage of drugs prescribed in generic was (64\%) and (78.8\%) were from the Essential Drug List (EDL). Calcium Channel Blockers (CCB, 71.7\%) and Biguanides (B, 92.4\%) were the most prescribed CVD and anti-diabetic drug. The majority of the CVD (74.5\%) and diabetes $(63.6 \%)$ patients were on combination therapy. The most frequent CVD combination was CCB plus Angiotensin-Converting Enzyme Inhibitors/Angiotensin Receptor Blockers (29.7\%). Compared to men, the proportion of females taking one or more CVD (61.3\%) or antidiabetic (56.4\%) was higher.

Conclusion: The prescribing indicators are not optimal in Abuja district hospitals. Women received more treatment for cardiovascular and diabetes diseases than men while the age range of 41-60 was more treated than other age groups.

Keywords: Cardiovascular, Anti-diabetic, Prescription pattern, Prescribing indicators, District hospitals

(C) 2019 The Authors. Published by Innovare Academic Sciences Pvt Ltd. This is an open-access article under the CC BY license (http://creativecommons.org/licenses/by/4.0/) DOI: http://dx.doi.org/10.22159/ijpps.2019v11i9.34525

\section{INTRODUCTION}

Non-Communicable Diseases (NCDs) is a global health threat affecting men and women in their most productive years. In 2016 NCDs were responsible for more than $70 \%$ of the global deaths [1]. Presently an epidemiological transition has taken place in lowermiddle-income countries [2] where NCDs constitute more than $60 \%$ of deaths in the region [1]. Cardiovascular diseases (CVDs) and diabetes were responsible for more than $50 \%$ of mortality due to NCDs in lower-middle-income countries [1]. Global Health Estimates in 2016 showed that CVDs and diabetes accounted for $29 \%$ of Years of Life Lost and $40.7 \%$ of deaths due to NCDs among Nigerian men and women $[1,3]$. In Nigeria, the prevalence of CVDs has not been established but existing evidence shows an increase in the prevalence of risk factors like hypertension and obesity $[4,5]$. The prevalence of diabetes in Nigeria ranges between $4.04 \%$ [6] to $5.77 \%$ [7]. With these increases, hospital consultations and attendant drug prescription which is an integral part of the management of CVDs and diabetes are likely to assume an upward and different trend. Consequently, there is a need to evaluate the quality of care received by the patients in terms of prescription. Existing evidence suggests that Cardiovascular (CV) drugs and antidiabetic drugs are among the highest therapeutic drug class prescribed in the outpatient $[8,9]$. The WHO recognizes the investigation of prescription as an objective method to describe drug use in health facilities [10]. Evaluation of prescription pattern and prescribing indicators can describe the prevailing prescription trend and assess the extent of rational drug use. Drug use study can be used to evaluate the healthcare needs of people according to age and sex at various levels of the health care system and this may contribute to adjustments in the drug policy of a country's health care system. This is particularly important in Nigeria where drug products exist both as a single agent and fixed-dose combinations.
The district hospitals in FCT are at the center of the provision of care for CVD and diabetes, and make a good site for an investigation into the prescription pattern.

There are variations in the reports of prescription patterns for CVDs and diabetes drugs, studies have reported Calcium Channel Blockers (CCB) [11-13] or Angiotensin-Converting Enzyme Inhibitor (ACEI) $[14,15]$ as the most utilized class of antihypertensive drugs. Other studies have documented diuretics $[16,17]$ as the most utilized CVD. Reports on the prescription pattern of anti-diabetics documented sulphonylureas $[14,18]$ or metformin [19] as the most utilized class of diabetes drug. However, inherent differences exist in prescription patterns across countries and even among similar health institutions of the same country, which necessitates more information on the pattern of use of drugs for these diseases. With more drugs being registered in Nigeria, there is always a gap in the knowledge of the use of drugs. Also, the guidelines on the management of CVDs and diabetes are not gender or age-specific on classes of a drug to use and it is not clear whether the prescription is the same for different gender and age group. This study was undertaken to assess prescription patterns for CVD and diabetes and adherence to WHO prescribing indicators in two secondary health institutions.

\section{MATERIALS AND METHODS}

Methods

\section{Study design and setting}

This retrospective study was conducted in Abuja District Hospitals in Nigeria from June to August 2018. Abuja is the Federal Capital Territory (FCT). FCT has thirteen district hospitals that are established and managed by the FCT Hospital Management Board. The operations of clinical services in these hospitals differ to some extent as they do not all have the same type of specialists. Two 
district hospitals were purposively selected out of the thirteen district hospitals. Asokoro and Maitama District Hospitals were chosen because they maintain an accessible electronic medical database that covers the period of the study and runs a Medical Outpatient Department (MOPD). Information in the database of pharmacy department include patient identification number, date of birth, date of prescription, sex, occupation, drugs prescribed, clinic where the prescription is being generated from, source of funding for the treatment, The Medical Outpatient Department (MOPD) holds a CV and diabetes clinic on two separate days of the week.

\section{A sampling of the prescriptions}

Using the information provided from the pharmacy records on the number of cardiovascular (CV) drugs and anti-diabetics dispensed for the period, the total prescriptions containing a cardiovascular drug and/or anti-diabetic were estimated to be 7279. The consultation days and prescriptions containing cardiovascular (CV) and/or anti-diabetic drugs were selected using systematic random sampling. The two consultation days were listed and alternate days were selected. On each day, every fourth prescription from MOPD was selected. Prescriptions included in the study were those containing at least one $\mathrm{CV}$ and/or anti-diabetic drug prescribed from MOPD for patients above $18 \mathrm{y}$. cardiovascular drugs are those used for hypertension and heart failure. Excluded prescriptions are those written without sex, age. There was no replacement.

\section{Data collection}

Data were collected using a modified WHO prescribing indicator data collection form. The age, sex, occupation, source of funding, cardiovascular drugs, anti-diabetic drugs, and other drugs in the prescription were collected. According to WHO [10] guide for investigating drug use pattern in facilities, at least 600 prescriptions must be sampled. A total of 1009 prescriptions (491 and 518) from Maitama and Asokoro hospitals respectively were systematically sampled out to assess the prescription pattern and WHO prescribing indicators. Ethical approval was received from FCT and Asokoro District Hospital Health Research Ethics Committee with the approval number FHREC/2018/01/48/26-04-18 and FCTA/HHSS/ $\mathrm{ADH} / \mathrm{EC} / 0055 / 18$ respectively. An approval letter was also given by Maitama District Hospital.

\begin{abstract}
Analysis of data
The data were coded into Statistical Package for the Social Sciences for Window (IBM SPSS version 21) and subsequently analyzed using descriptive statistics. Association between prescriptions, gender, and age were tested with chi-square. P-value $<$ or $=$ to 0.05 was considered statistically significant. Results were expressed in frequencies, percentages, numbers, means and standard deviations.
\end{abstract}

To evaluate the prescription pattern, the number of cardiovascular and antidiabetic drugs was determined for each prescription. The drugs were classified according to the Anatomical Therapeutic Chemical (ATC) code. The cardiovascular drugs include calcium channel blockers-C08, agents acting on the rennin angiotensin system-C09, diuretics-C03, beta-blocking agents-C07, centrally acting drugs-C02A, and cardiac therapy-C01. The anti-diabetic was classified into biguanides-A10BA, sulfonylureas-A10BB, dipeptidyl peptidase (DPP-4) inhibitors-A10BH and insulin-A10A. The prescription pattern for cardiovascular and anti-diabetic drugs was evaluated according to gender and age. The percentage of cardiovascular and anti-diabetic drugs prescribed in generic and from the Essential Drug List (EDL) was also assessed. Nigeria and FCT EDL were utilized. The WHO prescribing indicators as recognized by the World Health Organization/International Network for Rational Use of Drugs (WHO/INRUD) were analyzed for the prescriptions. The prescribing indicators include the average number of drugs per prescription, percentage of drugs prescribed by generic name, percentage of encounters with an antibiotic prescribed, percentage of prescriptions with an injection prescribed, percentage of drugs prescribed from essential drug list. Other indicators analyzed were the average number of cardiovascular and anti-diabetic drugs per prescription, percentage of cardiovascular or anti-diabetic drug prescribed in generic and percentage of cardiovascular or anti-diabetic drug prescribed from EDL.

\section{RESULTS}

\section{Demographic characteristics}

The mean age of the patients was $52.6 \pm 12.5$ similar in both genders (range 19-95 y). Prescriptions for females constituted 593 (58.8\%). Approximately $55 \%$ of the prescription was written for patients between 41-60 y (table 1).

Table 1: Age and sex distribution

\begin{tabular}{llll}
\hline Variables & Males & Females & Total \\
\hline Number $(\%)$ & $416(41.2)$ & $593(58.8 \%)$ & $1009(100 \%)$ \\
Age & & & \\
mean \pm SD & $52.64 \pm 12.2$ & $52.51 \pm 12.8$ & $189(18.7 \%)$ \\
$19-40$ & $73(7.2)$ & $116(11.5)$ & $553(54.8 \%)$ \\
$41-60$ & $225(22.3)$ & $328(32.5)$ & $267(26.5)$ \\
$>60$ & $118(11.7)$ & $149(14.9)$ & \\
\hline
\end{tabular}

$\mathrm{Sd}=$ standard deviation

\section{Prescribing indicators}

The average number of drugs per prescription was $3.3 \pm 1.6$, with a range of 1-9 drugs. The commonest number of drugs was 3 drugs, while the least was 9 drugs. Percentage of drug prescribed in generics was $64 \%$ and $78.8 \%$ were from Nigeria Essential Drug List (EDL) or FCT EDL. Prescriptions for antibiotics and injections were $7 \%$ and $5.7 \%$ respectively. Insulin constituted $65.5 \%$ of the injections prescribed. Prescriptions for cardiovascular and antidiabetic drugs were (855) $84.7 \%$ and 335 (33.2\%) respectively, while $180(17.8 \%)$ of the prescriptions contain cardiovascular and anti-diabetic drugs. The total number of cardiovascular drugs prescribed was 1728 (2.0/prescription) while anti-diabetic was 573 (1.7/prescription). Among all prescribed cardiovascular and diabetes medicines, s-amlodipine, irbesartan, enalapril, perindopril, nebivolol, torasemide indapamide, and sitagliptin were neither in Nigeria nor FCT EDL. Percentage of cardiovascular drug and antidiabetic drugs prescribed in generics was $74.6 \%$ and $15.5 \%$ respectively. Prescriptions paid from insurance were $7.2 \%$. The prescribing indicators are summarized in table 2. Other drug classes most prescribed were antiinfectives $18.4 \%$, antiplatelets $17.9 \%$, antipyretics/analgesics $15.5 \%$, multi-vitamins/supplements $14.6 \%$, lipid regulating drugs $8.2 \%$, gastrointestinal drugs $8.1 \%$ and anxiolytics/antidepressant $5.8 \%$.

\section{Percentage prescription of cardiovascular and anti-diabetic drugs}

The frequency of use of the CVD was Calcium Channel Blockers (CCB, 71.7\%), Angiotensin-Converting Enzyme Inhibitors/Angiotensin Receptor Blockers (ACEI/ARB, 67.8\%), Diuretics (D, 43.6\%), Beta Blockers (BB, 7.2\%), Cardiac Glycosides (CG, 6.3\%) and Centrally Acting (CA, 5.9\%). Considering the specific agents, Amlodipine was the most prescribed CVD, with a frequency of 486 (56.9\%), followed by Lisinopril 353 (41.3\%), hydrochlorothiazide 249 (24.7\%) and telmisartan 133 (15.6\%). The least prescribed drug was nebivolol $(0.1 \%)$, (table 3). Biguanide (B) was the commonly prescribed antidiabetic $(92.4 \%)$ followed by Sulphonylureas (SU, 56.5\%) while 
Dipeptidyl peptidase (DPP-4) inhibitors (11.1\%) were the least prescribed (table 4). For the CVD, CCB (11.6\%), ACEI/ARB (7\%), D (4.7\%), BB (1.2\%) and CA (1.1\%) were prescribed as monotherapy. The most occurring combination therapy was CCB $(38 \%)$ in 2 drug therapy; diuretic $(22.5 \%)$ in 3 drug therapy; BB and diuretics $(1.8 \%)$ in 4 drug therapy. Only $(0.1 \%) 5$ drug combination was observed. Examination of the anti-diabetic drugs revealed that biguanides, (28.7\%), Insulin (4.5\%) and Sulphonylurea (3.3\%) were prescribed as monotherapy. Biguanide was the most frequent drug in combination therapy; 2-drugs (56.5\%), 3-drugs (6.9\%), (table 5). The commonest CVD combination observed was CCB plus ACEI/ARB (29.7\%), followed by CCB plus diuretic (5.7\%). In 3-drug combination, CCB plus ACEI/ARB plus D (17.8\%) was seen followed by ACEI/ARB plus D plus CG (2.3\%). Biguanides plus sulphonylureas (47.5\%) were the commonly used 2 drugs combination. Sixty-one (6\%) of the CV and 46 $(4.5 \%)$ of anti-diabetic prescriptions were fixed-dose combinations.

Table 2: Prescribing indicators

\begin{tabular}{|c|c|}
\hline Variables & $(\mathbf{M} \pm$ Sd) \\
\hline Average number of drugs & $3.3 \pm 1.6$ \\
\hline Cardiovascular drugs & $2.02 \pm 0.8$ \\
\hline Females & $2.03 \pm 0.8$ \\
\hline Males & $2.01 \pm 0.7$ \\
\hline Diabetic drugs & $1.71 \pm 0.6$ \\
\hline Females & $1.74 \pm 0.6$ \\
\hline Males & $1.68 \pm 0.6$ \\
\hline$\%$ Generics & 64 \\
\hline$\%$ Cardiovascular & 74.6 \\
\hline \% Diabetes & 15.5 \\
\hline$\%$ Antibiotics & 7 \\
\hline$\%$ Injections & 5.7 \\
\hline$\%$ Essential drug list & 78.8 \\
\hline$\%$ Cardiovascular & 97 \\
\hline \% Diabetes & 98 \\
\hline
\end{tabular}

$\mathrm{M} \pm \mathrm{sd}=$ mean \pm Standard deviation

Table 3: Prescription pattern of cardiovascular drugs

\begin{tabular}{|c|c|c|c|c|}
\hline Drug class & Drug name & ATC code & $\mathbf{N}$ & $(\%)$ \\
\hline \multirow[t]{4}{*}{$\mathrm{CCB}$} & & C08 & 612 & 71.7 \\
\hline & Amlodipine & C08CA01 & 486 & 56.9 \\
\hline & Nifedipine & C08CA05 & 116 & 13.6 \\
\hline & S-amlodipine & $\mathrm{N} / \mathrm{A}$ & 10 & 1.2 \\
\hline \multirow[t]{9}{*}{ ACEI/ARB } & & C09 & 579 & 67.8 \\
\hline & Lisinopril & С09AA03 & 353 & 41.3 \\
\hline & Enalapril & C09AA02 & 3 & 0.4 \\
\hline & Ramipril & C09AA05 & 19 & 2.2 \\
\hline & Perindopril & C09AA04 & 2 & 0.2 \\
\hline & Telmisartan & С09CA07 & 133 & 15.6 \\
\hline & Valsartan & С09CA03 & 35 & 4.1 \\
\hline & Losartan & C09CA01 & 32 & 3.7 \\
\hline & Irbesartan & C09CA04 & 2 & 0.2 \\
\hline \multirow[t]{7}{*}{ Diuretics } & & $\mathrm{C} 03$ & 526 & 43.6 \\
\hline & Hydrochlorothiazide & С03АA03 & 249 & 20.6 \\
\hline & Spironolactone & C03DA01 & 89 & 7.3 \\
\hline & Furosemide & C03CA01 & 79 & 6.5 \\
\hline & Amiloride & C03DB01 & 77 & 6.4 \\
\hline & Torasemide & C03CA04 & 25 & 2.1 \\
\hline & Indapamide & C03BA11 & 9 & 0.7 \\
\hline \multirow[t]{5}{*}{ Beta-blocker } & & $\mathrm{C} 07$ & 60 & 7.1 \\
\hline & Atenolol & С07АB03 & 32 & 3.8 \\
\hline & Bisoprolol & C07AB07 & 20 & 2.4 \\
\hline & Propranolol & C07AA05 & 7 & 0.8 \\
\hline & Nebivolol & C07AB12 & 1 & 0.1 \\
\hline Centrally acting & Methyldopa & $\mathrm{C} 02 \mathrm{AB}$ & 50 & 5.9 \\
\hline Cardiac glycoside & Digoxin & C01AA05 & 54 & 6.3 \\
\hline
\end{tabular}

$\mathrm{CCB}=$ Calcium Channel Blockers, $\mathrm{ACEI}=$ Angiotensin-Converting Enzyme Inhibitors, $\mathrm{ARB}=$ Angiotensin Receptor Blockers, N/A = Not Available, $\mathrm{N}=$ Number of prescriptions

\section{Prescription of the cardiovascular and diabetic drug by gender and age}

The frequency of treatment for cardiovascular diseases $(61.3 \%)$ and diabetes $(56.4 \%)$ was higher in females. The proportion of patients treated with one (15.8\% vs. $9.7 \%)$, two (29.4 vs. 19.5$)$ or three $(14.7 \%$ vs. $9 \%)$ CVD was higher in females than men. Only $(0.3 \%)$ men received four anti-diabetic drugs. Percentage use of CV and anti-diabetic drug prescription by gender are summarized in fig. 1 and fig. 2 , respectively. The prescriptions for CCB $(P=0.014)$, ACEI/ARB $(P=0.02)$, centrally acting drugs $(p=0.001)$ and diuretics $(P=0.05)$ were significantly higher in females. The percentage of $\mathrm{BB}$ prescription was higher in females but no significant difference. For diabetic drugs, higher proportions of males received a prescription of sulphonylureas and biguanides, while more females received DPP-4 inhibitors and insulin (table 6).

Table 7 compares the use of CVD and anti-diabetic drug classes by age. The proportion of prescriptions for CVD and the anti-diabetic drug was higher among the ages of 41-60. The use of CCB $(\mathrm{P}=<0.001)$, ACEI/ARB $(\mathrm{P}=<0.001)$, diuretics $(\mathrm{P}=<0.001)$, centrally acting drugs $(\mathrm{P}=<0.001)$, metformin $(\mathrm{P}=<0.001)$ and insulin $(\mathrm{P}=<0.001)$ was significantly higher in people within the age of 41-60. 
Table 4: Prescription pattern of anti-diabetic drugs

\begin{tabular}{|c|c|c|c|c|}
\hline Drug class & Drug name & ATC code & $\mathbf{N}$ & (\%) \\
\hline Biguanide & Metformin & A10BA02 & 309 & 92.4 \\
\hline \multirow[t]{3}{*}{ Sulphonylurea } & & $\mathrm{A} 10 \mathrm{BB}$ & 191 & 56.5 \\
\hline & Glimepiride & A10BB12 & 173 & 51.2 \\
\hline & Glibenclamide & A10BB01 & 18 & 5.3 \\
\hline \multirow[t]{4}{*}{ Insulin } & & A10A & 38 & 11.4 \\
\hline & BI 30/70 & A10AD30 & 31 & 9.3 \\
\hline & Soluble insulin & $\mathrm{A} 10 \mathrm{AB} 01$ & 4 & 1.2 \\
\hline & Glargine & A10AE04 & 3 & 0.9 \\
\hline \multirow[t]{3}{*}{ DPP-4 I } & & A10BH & 35 & 11.1 \\
\hline & Vildagliptin & A10BH02 & 24 & 7.6 \\
\hline & Sitagliptin & A10BH01 & 11 & 3.5 \\
\hline
\end{tabular}

BI 30/70 = Biphasic isophane insulin 30\% soluble 70\% isophane, DPP-4I = Dipeptidyl Dipeptidase-4-Inhibitors N= Number of prescriptions

Table 5: Proportion of drug class as monotherapy and combination therapy $\mathrm{N}(\%)$

\begin{tabular}{|c|c|c|c|c|c|}
\hline Drug class & 1-drug & 2-drugs & 3-drugs & 4-drugs & 5-drugs \\
\hline CCB & $99(11.6)$ & $325(38)$ & $174(20.4)$ & $13(1.6)$ & $1(0.1)$ \\
\hline ACEI/ARB & $60(7.0)$ & $317(37.1)$ & $186(21.8)$ & $15(1.8)$ & $1(0.1)$ \\
\hline Diuretic & $40(4.7)$ & $122(14.2)$ & 195 (22.8) & $15(1.8)$ & $1(0.1)$ \\
\hline Beta-Blocker & $10(1.2)$ & $28(3.3)$ & $16(2)$ & $5(.6)$ & $1(0.1)$ \\
\hline Centrally acting & $9(1.1)$ & $20(2.4)$ & $14(1.6)$ & $6(.7)$ & $1(0.1)$ \\
\hline Digoxin & - & $24(2.8)$ & $24(2.8)$ & $6(.7)$ & - \\
\hline \multicolumn{6}{|l|}{ Antidiabetic } \\
\hline Biguanides & $96(28.7)$ & $189(56.5)$ & $23(6.9)$ & $1(0.3)$ & - \\
\hline Sulphonylureas & $11(3.3)$ & $159(47.5)$ & $18((5.4)$ & $1(0.3)$ & - \\
\hline Insulin & $15(4.5)$ & $13(3.9)$ & $9(2.7)$ & $1(0.3)$ & - \\
\hline DPP-4I & - & $17(5.1)$ & $19(5.7)$ & $1(0.3)$ & - \\
\hline
\end{tabular}

$\mathrm{CCB}=$ Calcium Channel Blockers, ACEI = Angiotensin Converting Enzyme Inhibitors, ARB = Angiotensin Receptor Blockers, DPP-4I = Dipeptidyl Dipeptidase-4-Inhibitors., N= Number of prescriptions

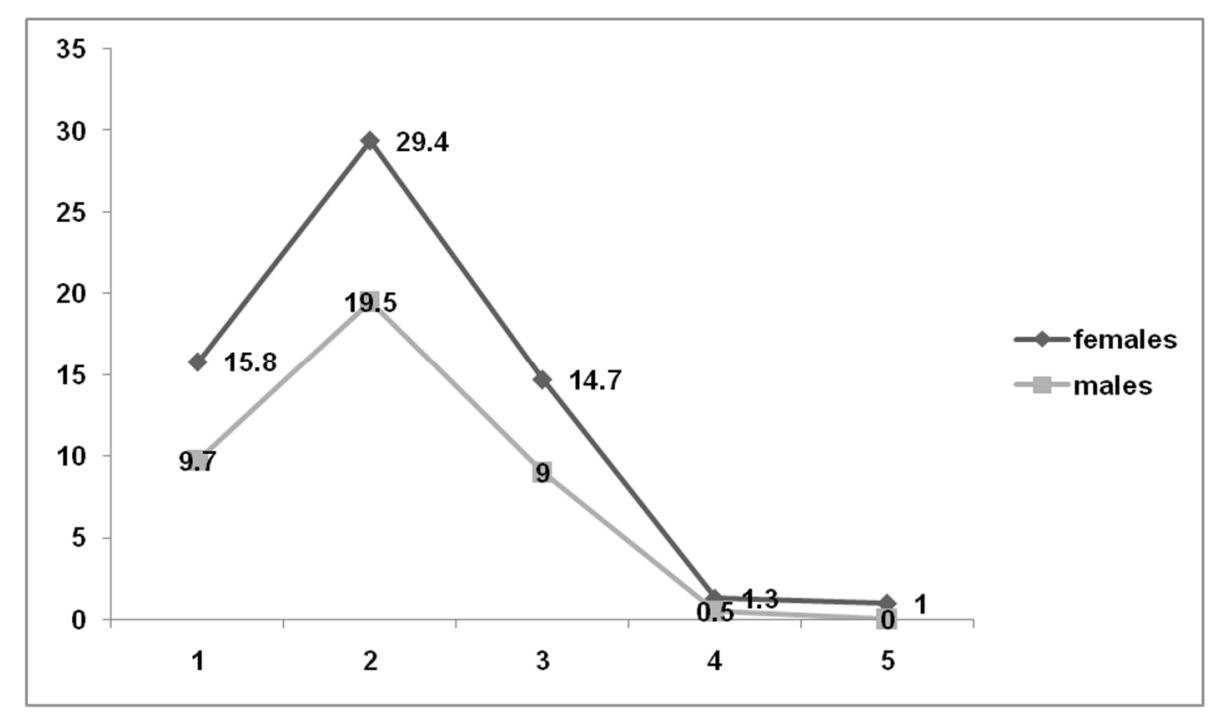

Fig. 1: Percentage of CVD use by gender, CVD= Cardiovascular drug

Table 6: Pattern of prescription of cardiovascular and diabetes drugs by gender N (\%)

\begin{tabular}{|c|c|c|c|c|}
\hline Therapeutic group & Drug class & Females & Males & P-value \\
\hline \multirow[t]{6}{*}{ CVD } & CCB & $364(61.4)$ & $248(59.6)$ & $0.014^{*}$ \\
\hline & ACEI/ARB & $350(59)$ & $229(55)$ & $0.002^{*}$ \\
\hline & Diuretics & $227(38.3)$ & $146(35.1)$ & $0.050^{*}$ \\
\hline & Beta-blocker & $43(7.3)$ & $17(4.1)$ & 0.088 \\
\hline & Centrally acting & $41(6.9)$ & $9(2.2)$ & $0.001^{*}$ \\
\hline & Digoxin & $39(6.6)$ & $15(3.6)$ & $0.039 *$ \\
\hline \multirow[t]{4}{*}{ Antidiabetics } & Sulphonylureas & $105(17.7)$ & $86(20.7)$ & 0.296 \\
\hline & Biguanides & $172(29)$ & $137(32.9)$ & 0.183 \\
\hline & DPP-4 I & $25(4.2)$ & $10(2.4)$ & 0.490 \\
\hline & Insulin & $26(4.4)$ & $12(2.9)$ & 0.431 \\
\hline
\end{tabular}

$\mathrm{CCB}=$ Calcium Channel Blockers, ACEI = Angiotensin-Converting Enzyme Inhibitors, ARB = Angiotensin Receptor Blockers, DPP-4I = Dipeptidyl Dipeptidase-4-Inhibitors, $\mathrm{N}=$ Number of prescriptions, ${ }^{*}=\mathrm{P}$ significant at $\leq 0.05$ 


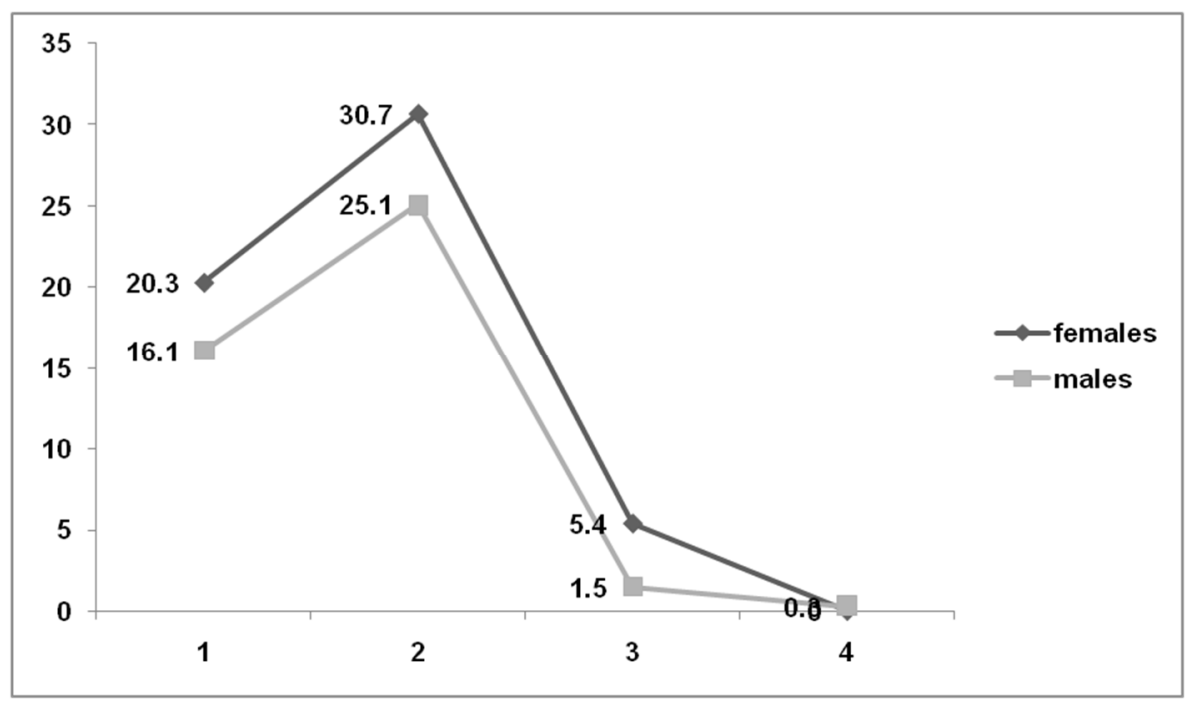

Fig. 2: Percentage use of antidiabetic drug by gender

Table 7: Pattern of prescription of cardiovascular and diabetic drugs by age $\mathrm{N}(\%)$

\begin{tabular}{llllll}
\hline Therapeutic group & Drug class & $\mathbf{1 9 - 4 0}$ & $\mathbf{4 1 - 6 0}$ & $\mathbf{> 6 0}$ & \multicolumn{1}{c}{ P value } \\
\hline CVD & CCB & $118(19.3)$ & $339(55.4)$ & $155(25.3)$ & $<0.001^{*}$ \\
& ACEI/ARB & $90(15.5)$ & $314(54.2)$ & $175(30.2)$ & $<0.001^{*}$ \\
& Diuretics & $71(19)$ & $198(53.1)$ & $104(27.9)$ & $<0.001^{*}$ \\
& Beta blocker & $13(21.7)$ & $34(56.7)$ & $13(21.7)$ & 0.836 \\
& Centrally acting & $21(42)$ & $25(50)$ & $4(8)$ & $<0.001^{*}$ \\
Anti-diabetic & Digoxin & $10(18.5)$ & $24(44.4)$ & $20(37)$ & 1.71 \\
& Sulphonylureas & $14(7.3)$ & $114(59.7)$ & $63(33)$ & 0.009 \\
& Biguanides & $24(7.8)$ & $181(58.6)$ & $104(33.7)$ & $<0.001^{*}$ \\
& DPP-4 Inhibitors & $1(2.9)$ & $21(60)$ & $13(37.1)$ & 0.658 \\
& Insulin & $10(26.3)$ & $24(63.2)$ & $4(10.5)$ & $<0.001^{*}$ \\
\hline
\end{tabular}

$\mathrm{CCB}=$ Calcium Channel Blockers, ACEI $=$ Angiotensin-Converting Enzyme Inhibitors, $\mathrm{ARB}=$ Angiotensin Receptor Blockers, DPP-4I $=$ Dipeptidyl Dipeptidase-4-Inhibitors, $\mathrm{N}=$ number of prescriptions, ${ }^{*}=\mathrm{P}$ significant at $\leq 0.05$

\section{DISCUSSION}

This present study assessed the prescribing indicators and prescription patterns for NCDs (CVDs and diabetes) medicines in the outpatient clinic. Prescription reflects how the clinician interprets the patient condition, plans for the management and the nature of the healthcare system in the country. The prevalence of treatment was higher among women (58.8\%), which has been documented by previous reports in Nigeria 59.2\% [19] 57.4\% [20] and other countries Korea 53. 6\% [21] and India 55.48\% [11]. However, other studies reported a higher treatment rate in men $[12,22]$. Our report might relate to the recent report of the high prevalence of hypertension and obesity among women in Nigeria [23]. The results indicated that most of the patients were in the age range of 41-60, which is consistent with the study by Krishna et al. [22]. This shows that CVDs and diabetes affect people in the most productive years of their lives.

Our results showed the average number of drugs per prescription to be 3.3, which is similar to 3.4 reported in Pakistan [24] but higher than the ideal WHO standard of 1.6-1.8 [10] and 2.6 [19] reported in Southeastern Nigeria. However, higher values have been reported in Southwest Nigeria 3.9 [25], 5.8 [26], India 5.64 [11], 7.56 [15], Pakistan 4.63[14]. The high number of drugs in our study is probably due to the type of patient prescription included in this study. Already, guidelines on the management of CVD recommend combining drugs from different pharmacological classes to prevent morbidity associated with CVD [27] and the diabetic patient often requires an additional drug to achieve glycaemic control [28]. The fixed-dose combination is recommended to reduce pill burden but usually comes at a higher cost than two separate products [29]. In Nigeria, health insurance is not yet common, so the benefit of the pill burden reduction is usually weighed carefully against the cost. For instance, in our study, a fixed-dose combination was seen in only $6 \%$ and $4.6 \%$ of $\mathrm{CV}$ and diabetic prescription respectively. Also, most patients with CVD and diabetes are known to have other conditions that will require treatment. The average number of $\mathrm{CV}$ drugs per prescription was 2.0, similar in both gender and close to previous reports on antihypertensive drugs in Nigeria 2.25 [16], 2 [30]. In contrast, a lower value was reported in South India at 1.78 [12]. The average number of diabetic drug per prescription was 1.7, also similar in both gender and consistent with the report of a previous study on anti-diabetic prescription in Southern Nigeria [20]. The result is expected as most of the prescription contains at least two $\mathrm{CV}$ or anti-diabetic. The generic prescription in this study $64 \%$ for all drugs, $74.6 \% \mathrm{CV}$ drugs, and $15.5 \%$ for diabetic drugs are lower than the WHO standard $100 \%$ and differ from reports in Nigeria and other countries. Higher values have been reported in Nigeria $72.2 \%$ [19] Pakistan 71.6\% [24], India 89.2\% [11], Ethiopia 97\%. [31] However, lower generic prescription was recorded in Nigeria $42.7 \%$ [32], Pakistan 56\% [33]. Southern India 2.5\% [34], 19.4\% [35]. It is surprising that generic prescription was not optimal in our study especially the diabetic drugs, as the hospitals are established and managed by the government. Generic prescribing encourages stocking of various brands which will improve accessibility to the medicines. Again generic prescription leads to clarity of information among the health professionals [36]. The poor generic prescribing may be attributed to physicians' doubt towards prescribing low-cost generic medicines for hypertensive and diabetic patients [37].

The percentage of injections $5 \%$ in this study is within WHO ideal value and similar to $4 \%$ [32] reported in Nigeria. In contrast, lower values have been reported in other similar studies in India 3.98\% [11]. This is possible as CV injectable drugs are mostly used in emergency and inpatients. Insulin constituted a large percentage of the injections prescribed which is supported by the report of Adibe 
et al. [19]. The percentage of encounters with antibiotics was $7 \%$ higher than $1.7 \%$ [19] reported in southern Nigeria but lower than another Nigeria study 26.8\% [32]. However, higher values have been reported in Ethiopia 58\% [38] 82.5\% [31] Pakistan 48.9\% [24]. This is expected as patients in our study are specialized, unlike the other studies that included prescriptions from all departments.

The percentage of drugs prescribed from EDL in this study was $78.8 \%$ which is lower than the WHO ideal value of $100 \%$. Other studies recorded higher prescription from EDL Nigeria 94\% [32], Ethiopia 92\% [31], Pakistan 98.8\% [33], India 99.8\% [34]. Most of the CV (97\%) and diabetic (98\%) drugs prescribed are on the EDL. Prescription of multivitamins, supplements, and analgesics constituted most of the drugs that were not on EDL. We draw attention to the use of multivitamins and supplements, as their use exceeded the use of lipid regulating drugs which are considered useful for cardiovascular and diabetic patients.

There was a high prescription of CCB, particularly amlodipine in FCT district hospitals. This was reported in some other studies $[11,12,39,40]$ while CCB has been reported as least prescribed $[22$, 41]. Agents that act on the renin-angiotensin system hold a good share of the prescription, with Lisinopril and Telmisartan leading in the class similar to other studies $[15,41]$. Other Nigeria study reported diuretic as most utilized $[16,17,30]$. Our report reflects a shift from the traditional prescription of diuretics in Nigeria. This is not surprising given the report that CCB either alone or in combination with other drugs is not inferior to diuretics in reducing cardiovascular effect [27,42]. Also, a diuretic is known to affect glucose homeostasis and lipid profile [27] this might have favored the use of CCB and drugs that act on the renin-angiotensin system in our study as it included diabetic patients. Over the years, a low price must have favored the use of diuretics, but with many generic CCB products being available, it is possible that the cost benefits of diuretics are wearing out. Perindopril and Nebivolol are relatively new in Nigeria market which might account for their low prescription. The low use of enalapril is surprising as it has been in Nigeria for a long time, though it is not included in EDL, a recommended ACEI for patients with hypertensive heart disease. Even though Amlodipine was the most single-agent prescribed, we noted that Lisinopril and telmisartan combined took the same share of prescription with amlodipine. The high use of renin antagonists in these hospitals was unexpected because they are not recommended for hypertensive black patients [27]. On the other hand, they are known to confer renal protection for diabetic patients which might have prompted their use [27].

Biguanides were the mostly prescribed anti-diabetic as a single agent and in combination with other drugs, which is consistent with Nigeria's studies $[19,39]$. This is expected as metformin has been established to lower cardiovascular risk and confer better survival to diabetic patients compared to other anti-diabetics [43]. Metformin is also known to promote weight loss, which is beneficial in type 2 diabetic patients. DPP-4-inhibitors were the least prescribed which contrasts $[19,20,39]$. Their low prescription might be attributed to their recommendation as add on therapy and also they are new in the Nigerian market.

In our sample, a small proportion $22.5 \%$ of the patient was treated with monotherapy, this is supported by reports from Nigeria $2.5 \%$ [44], 20\% [45] and India 27.7\% [22]. In contrast, an Indian study [46] reported most CVD patients to be treated with monotherapy and Patel et al. [47] reported the use of monotherapy to treat diabetic patients. Our study is consistent with recommendations on the use of combination drugs from more than one class to manage CVD and diabetes [27,28]. Also, lower doses of different drugs ensure a better safety profile than a higher dose of one drug [27]. Besides, the study combined CV and diabetic drug which suggest that some patients have both conditions and must require more than one drug for compelling indication.

Considering gender difference in the use of CVD drugs, the use of CCB, ACEI/ARB and diuretics were significantly higher in women, which is similar to a US [48] report. However, another study [12] reported no significant difference in genders in the use of CVD drugs. Thiazide diuretic has been reported to adversely affect men sexually
[27], which might contribute to its low prescription in men. Gender difference in the use of CVD is still unclear. The gender difference in the use of antidiabetics was not significant, even though there is a high proportion of metformin and sulphonylureas prescribed for men, which is consistent with a Nigeria [20] report.

Regarding age difference, the age range of 41-60 received a significantly higher proportion of most of the prescription of CVD and diabetic drugs, which is in agreement with a previous report in South Nigeria [20]. This is probably due to an increased number of consultations for people within that age, which suggests that people of that age suffer CVD and diabetes more. The use of insulin was low in people $>60 \mathrm{y}$; this is possible because a high rate of hypoglycemia has been documented in the diabetic patient of that age group using insulin $[49,50]$.

A limitation on this study is that information on compelling indication which might drive prescription was not gathered through the prescription and the study could not assess the clinical outcome that might affect the change of prescription.

\section{CONCLUSION}

The prescribing indicators (mean number of drugs, percentage of drugs prescribed in generic and percentage prescribed from EDL) are not in conformity with WHO/INRUD recommendation. Calcium channel blockers replaced thiazide diuretics as the most prescribed $\mathrm{CV}$ drug, while Metformin is the most prescribed antidiabetic drug. Compared to men, more women are receiving treatment for CVD and diabetes and the most productive age of 41-60 are being treated for CVDs and diabetes in FCT district hospitals.

\section{AUTHORS CONTRIBUTIONS}

Nkeiruka Grace Osuafor collected the data, prepared and revised the manuscript. Chinwe Ukwe designed the study and Mattew Okonta analyzed the data. The submitted copy was approved by all the authors.

\section{CONFLICT OF INTERESTS}

Authors declare no conflict of interest

\section{REFERENCES}

1. WHO. Global Health Estimates 2016: Deaths by Cause, Age, Sex, by Country and by Region, 2000-2016. Geneva; 2018.

2. Maiyaki M, Garbati M. The burden of non-communicable diseases in Nigeria: in the context of globalization. Ann Afr Med 2014;13:1-0.

3. WHO. Global Health Estimates 2016: Disease burden by Cause, Age, Sex, by Country and by Region, 2000-2016. Geneva; 2018.

4. Akinlua JT, Meakin R, Umar AM, Freemantle N. Current prevalence pattern of hypertension in nigeria: a systematic review. PLoS One 2015;10:1-8.

5. Ekpenyong CE, Udokang NE, Akpan EE, Samson TK. Double burden, non-communicable diseases, and risk factors evaluation in sub-saharan Africa: the Nigerian experience. Eur J Sustain Dev 2012;1:249-70.

6. International Diabetes Federation. 5th IDF diabetes atlas; 2011. p. 106.

7. Uloko AE, Musa BM, Ramalan MA. Prevalence and risk factors for diabetes mellitus in Nigeria : a systematic review and metaanalysis. Diabetes Ther 2018;9:1307-16.

8. Karimi A, Haerizadeh M, Soleymani F, Haerizadeh M, Taheri F. Evaluation of medicine prescription pattern using World Health Organization prescribing indicators in Iran: a crosssectional study. J Res Pharm Pract 2014;3:39-45.

9. Khrime D, Kumar A, Pandey AN, Bansal N, Sharma U, Varma A. Antihypertensive drug utilization pattern and awareness in diabetic hypertensive patients at a tertiary care center. Int J Res Med Sci 2015;3:461-5.

10. WHO. How to investigate drug use in health facilities. Geneva; 1993.

11. Bhavika D, Prasanna V, Swathi B. Drug utilization study of antihypertensive drugs in a tertiary care hospital. Int J Basic Clin Pharmacol 2016;5:1580-5. 
12. Datta S. Utilization study of antihypertensives in a South Indian Tertiary Care Teaching Hospital and adherence to standard treatment guidelines. J Basic Clin Pharm 2017;8:33-7.

13. Ekwunife OI, Ubaka CM. Drug utilization review of antihypertensive therapy among patients with compelling indications in two hospitals in South-Eastern Nigeria. J Pharm Pharmacol Res 2011;2:25-8.

14. Riaz H, Brian G, Sajid B, Shahzad H, Mahmood S, Durdana. Evaluation of drug use indicators for non-communicable diseases in Pakistan. Acta Pol Pharm Res 2016;73:787-94.

15. Jainaf Nachiya RAM, Parimalakrishnan S, Ramakrishna RM. Study on drug utilization pattern of antihypertensive medications on out-patients and inpatients in a tertiary care teaching hospital: a cross-sectional study. Afr J Pharm Pharmacol 2015;9:383-96.

16. Ukwe CV, Ubaka CM. Antihypertensive drug prescribing in a tertiary hospital in eastern Nigeria. Trop J Pharm Res 2012;11:297-305.

17. Nwaka AL, Nduka SO, Osonwa UE, Anetoh M, Uzodinma U, Ele GN. Evaluation of the prescription pattern of antihypertensive agents in a tertiary health institution in Nigeria. Afr J Pharm Pharmacol 2015;9:540-6.

18. Agarwal AA, Jadhav PR, Deshmukh YA. Prescribing pattern and efficacy of anti-diabetic drugs in maintaining optimal glycemic levels in diabetic patients. J Basic Clin Pharm 2014;5:79-83.

19. Adibe MO, Aguwa CN, Ukwe CV, Okonta JM. Outpatient utilization of anti-diabetic drugs in southeastern Nigeria. Int J Drug Dev Res 2009;1:27-36.

20. Okoro NR, Nmeka C, Erah PO. Utilization study of anti-diabetes medicines at a tertiary care hospital in Nigeria. Futur J Pharm Sci 2017;4:109-15.

21. Lee SY, Bae J, Cho M, Lim NK, Park H. Antihypertensive drug use and gender difference in real-world practice: a Korean national health insurance database study. J Hypertens 2016;34:9-15.

22. Murti K, Khan MA, Dey A, Sethi MK, Das P, Pandey K. Prescription pattern of antihypertensive drugs and adherence to JNC-7 guidelines. Am J Pharmacol Toxicol 2015;10:27-31.

23. WHO. Non-communicable diseases country profiles; 2014. p. 323.

24. Atif M, Sarwar MR, Azeem M, Naz M, Amir S, Nazir K. Assessment of core drug use indicators using WHO/INRUD methodology at primary healthcare centers in Bahawalpur, Pakistan. BMC Health Serv Res 2016;16:684.

25. Eze UIH, Olowu AO. Prescribing patterns and inappropriate use of medications in elderly outpatients in a tertiary hospital in Nigeria. Trop J Pharm Res 2011;10:19-25.

26. Adisa R, Fakeye TO, Aindero VO. Evaluation of prescription pattern and patients' opinion on healthcare practices in selected primary healthcare facilities in Ibadan, South-Western Nigeria. Afr Heal Sci 2015;15:1318-29.

27. Chobanian AV, Bakris GL, Black HR, Cushman WC, Green LA, Arbor A, et al. The seventh report of the joint national committee on prevention, detection, evaluation, and treatment of high blood pressure. US Dep Heal Hum Serv 2004. p. 49.

28. Chinenye S, Ofoegbu E, Uloko A, Ogbera A, Kuku S, Johnson TO. Clinical practice guidelines for diabetes management in Nigeria. $2^{\text {nd }}$ ed. Diabetes Association of Nigeria; 2013. p. 28.

29. Bramlage P, Schmidt S, Sims H. Fixed-dose vs free-dose combinations for the management of hypertension-An analysis of 81958 patients. J Clin Hypertens 2018;20:705-15.

30. Ilesanmi SO, Ige Ok, Adebiyi AO. The managed hypertensive: the costs of blood pressure control in a Nigerian town. Pan Afr Med J 2012;12:96.

31. Bilal AI, Osman ED, Mulugeta A. Assessment of medicines use pattern using World Health Organization's prescribing, patient care and health facility indicators in selected health facilities in eastern Ethiopia. BMC Health Serv Res 2016;16:144-50.

32. Tamuno I, Fadare JO. Drug prescription pattern in a Nigerian tertiary hospital. Trop J Pharm Res 2012;11:146-52.
33. Atif M, Sarwar MR, Azeem M, Umer D, Rauf A, Rasool A, et al. Assessment of WHO/INRUD core drug use indicators in two tertiary care hospitals of Bahawalpur, Punjab Pakistan. J Pharm Policy Pract 2016;9:27.

34. Aravamuthan A, Arputhavanan M, Subramaniam K. Assessment of current prescribing practices using World Health Organization core drug use and complementary indicators in selected rural community pharmacies in Southern India. J Pharm Policy Pract 2017;10:1-6.

35. Sharif SI, Alabdouli AH, Sharif RS. Drug prescribing trends in a general hospital in Sharjah, United Arab Emirates. Am J Pharmacol Sci 2013;1:6-9.

36. Aki OA, El Mahalli AA, Awad A, Elkahky A. WHO/INRUD drug use indicators at primary healthcare centers in Alexandria, Egypt. J Taibah Univ Med Sci 2014;9:54-64.

37. Flood D, Mathieu I, Chary A, García P, Rohloff P. Perceptions and utilization of generic medicines in guatemala: a mixedmethods study with physicians and pharmacy staff. BMC Health Serv Res 2017;17:27.

38. Desalegn AA. Assessment of drug use patterns using WHO prescribing indicators at Hawassa University teaching and referral hospital, South Ethiopia: a cross-sectional study. BMC Health Serv Res 2013;13:170.

39. JM Okonta, SO Nduka, VE Idodo. Prescribing pattern of antihypertensive and antidiabetic agents in a secondary healthcare institution in Nigeria. J Pharm Sci Res 2013;5:12-7.

40. Panda BB, Pati MR, Sahu PK. Survey of a prescription pattern of antihypertensive drugs in hypertensive and diabetic hypertensive patients. Asian J Pharm Clin Res 2015;8:250-2.

41. Alba Leonel A, Carvajal A, Fierro I, Castillo NF. Prescription patterns of antihypertensives in a community health center in mexico city: a drug utilization study. Authors Fundam Clin Pharmacol 2016;30:276-81.

42. Oh GC, Lee H, Chung WJ, Youn H, Cho E, Sung K, et al. Comparison of effects between calcium channel blocker and diuretics in combination with angiotensin II receptor blocker on 24-h central blood pressure and vascular hemodynamic parameters in hypertensive patients: study design for a multicenter, double-blinded, active-controlled, phase 4 randomized trial. Clin Hypertens 2017;23:18.

43. Holman RR, Paul SK, Bethel AM, Matthews DR, Neil HAW. 10year follow-up of intensive glucose control in type 2 diabetes. New Engl J Med 2008;359:1577-89.

44. Bakare OQ, Goodman O, Kuyinu YA, Wright OK, Adeniran A, Odusanya 00. Antihypertensive use, prescription patterns, and cost of medications in a teaching hospital in lagos, nigeria. Niger J Clin Prac 2016;19:688-72.

45. Etuk E, Isezuo SA, Chika A, Akuche J, Ali M. Prescription pattern of antihypertensive drugs in a tertiary health institution in Nigeria. Ann Afr Med 2008;7:128-32.

46. Mahanjit K, Pranab KP, SwarnamonI D. Prescribing pattern of antihypertensive drugs in essential hypertension in medicine outpatients department in a tertiary care hospital. Asian Pharm Clin Res 2014;7 Suppl 2:142-4.

47. Patel B, Oza B, Patel KP, Malhotra SD, Patel VJ. Pattern of antidiabetic drugs uses in type-2 diabetic patients in a medical outpatient clinic of a tertiary care teaching hospital. Int J Basic Clin Pharmacol 2013;2:485-91.

48. Gu Q, Burt VL, Paulose Ram R, Dillon CF. Gender differences in hypertension treatment, drug utilization patterns, and blood pressure control among US adults with hypertension: data from the National Health and nutrition examination survey 1999-2004. Am J Hypertens 2008;21:787-98.

49. McCall AL. Insulin therapy and hypoglycemia. Endocrinol Metab Clin North Am 2012;41:57-87.

50. Hope SV, Taylor PJ, Shields BM, Hattersley AT, Hamilton W, Practice $\mathrm{M}$, et al. Are we missing hypoglycemia? elderly patients with insulin-treated diabetes present to primary care frequently with non-specific symptoms associated with hypoglycemia. Prim Care Diabe 2017;12:139-46. 